\title{
Where are my Dentures? An Unusual Complication after Total Knee Replacement
}

\author{
Nicholas L Kolodychuk ${ }^{1,2^{*}}$, Michael Casale ${ }^{1}$ and Bradford S Waddell ${ }^{1}$ \\ ${ }^{1}$ Ochsner Medical Center, 1401 Jefferson Hwy, New Orleans, USA \\ ${ }^{2}$ University of Queensland School of Medicine, Brisbane, Australia
}

Submission: June 28, 2017; Published: July 13, 2017

*Corresponding author: Nicholas L Kolodychuk, Ochsner Medical Center, University of Queensland School of Medicine 1401 Jefferson Hwy, New Orleans, LA 70115, USA, Tel: (360) 296-9260; Email: nkolodychuk@gmail.com

\begin{abstract}
Total knee replacement is a common and reliable procedure in the United States. We present a case of a 51-year-old female with an unusual post-operative complication from this procedure. Ingestion of foreign bodies is an uncommon problem in adults with ingestion of dentures being even rarer. While uncommon this situation can lead to serious morbidity in the patients it effects.
\end{abstract}

Keywords: Total knee Arthroplasty; Complication; Dentures; Foreign body

\section{Introduction}

Total knee replacement is a widely regarded as a reliable procedure for pain relief in the arthritic knee. In the United States alone it is estimated that more than 700,000 patients undergo total knee replacement annually [1]. While complications occur, they are usually related to the surgical site or are medical in nature. In this report, a patient sustained an unusual complication in the early postoperative period after total knee replacement.

\section{Case Report}

A 51-year-old female presented with left knee pain. The pain began incidentally and gradually worsened over a year. She had tried rest, ice and NSAIDs with little relief in her symptoms. Her pain was sharp and stabbing with activity, followed by a strong dull ache. Pain limited her activity. X-rays were ordered on the initial visit demonstrating tri-compartmental osteoarthritis (Figure 1). She was given a corticosteroid injection and physical therapy prescription. Six weeks later she returned with minimal relief from each. She was scheduled for left total knee replacement and underwent an intra-operatively uncomplicated left total knee replacement. On the morning of post-op day 1 , she complained of nausea recalcitrant to anti-emetics overnight. She stated she had misplaced her prosthetic dentures of her front bottom teeth, insisting she swallowed them. After discussion over the probabilities of the patient swallowing the dentures versus losing them, and the risks and benefits of $x$-ray investigation, neck $\mathrm{x}$-ray and abdominal $\mathrm{x}$-ray were ordered.

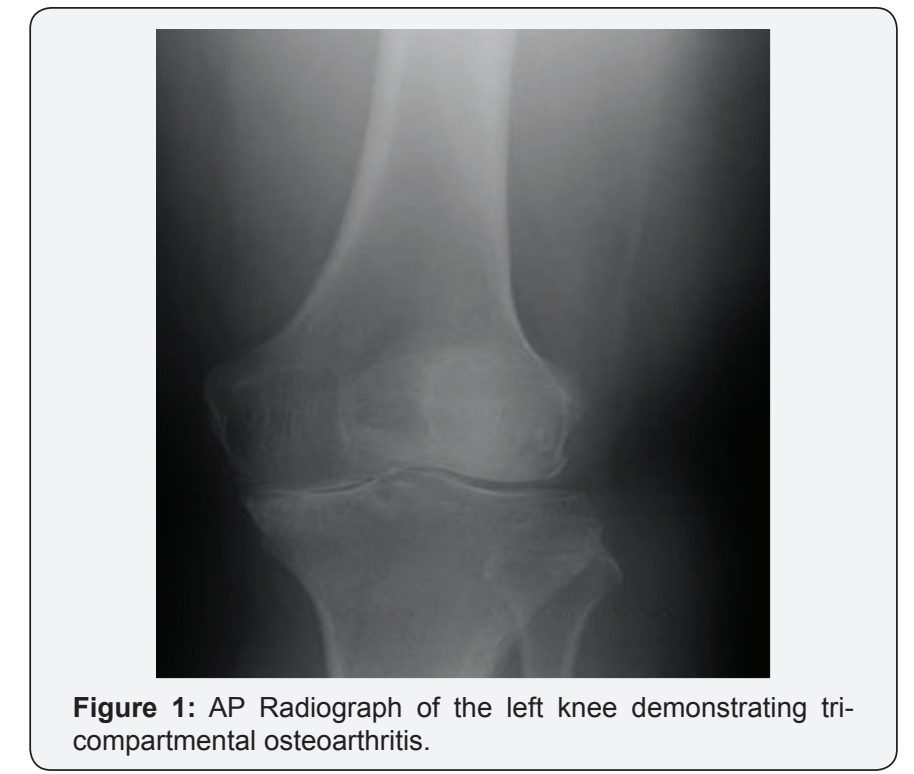

$\mathrm{X}$-ray of the neck showed the dentures in the mid-esophagus region of the patient's neck (Figure 2). General surgery was consulted and felt despite their size; they may pass without incident with time. Three hours later another abdominal x-ray demonstrated the dentures having passed into the stomach (Figure 3). The patient was discharged with general surgery follow-up and passed the dentures without incident at home. Early follow-up and now two-year follow-up has demonstrated satisfied patient with a well-functioning, stable prosthesis (Figures $4 \& 5$ ) and no ill-effects from the incident. 


\section{Orthopedics and Rheumatology Open Access Journal}

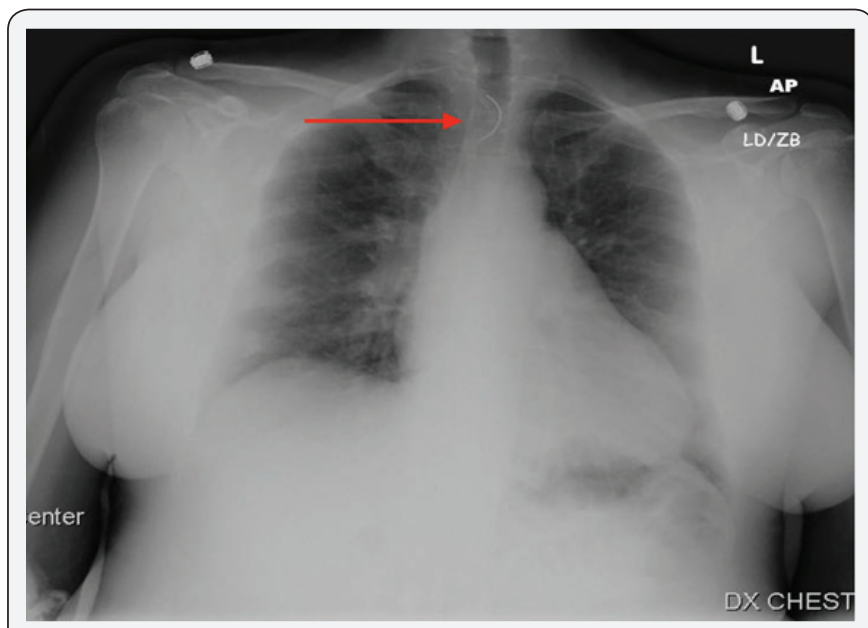

Figure 2: AP chest radiograph demonstrating dentures (red arrow) in the esophagus.

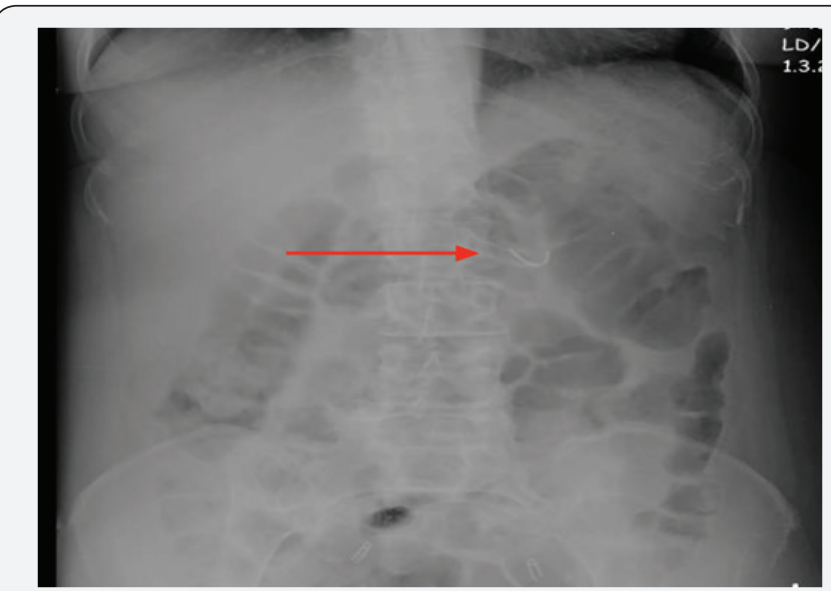

Figure 3: AP abdomen radiograph taken approximately 3 hours after Figure 2 demonstrating passage of dentures (red arrow) into the stomach.

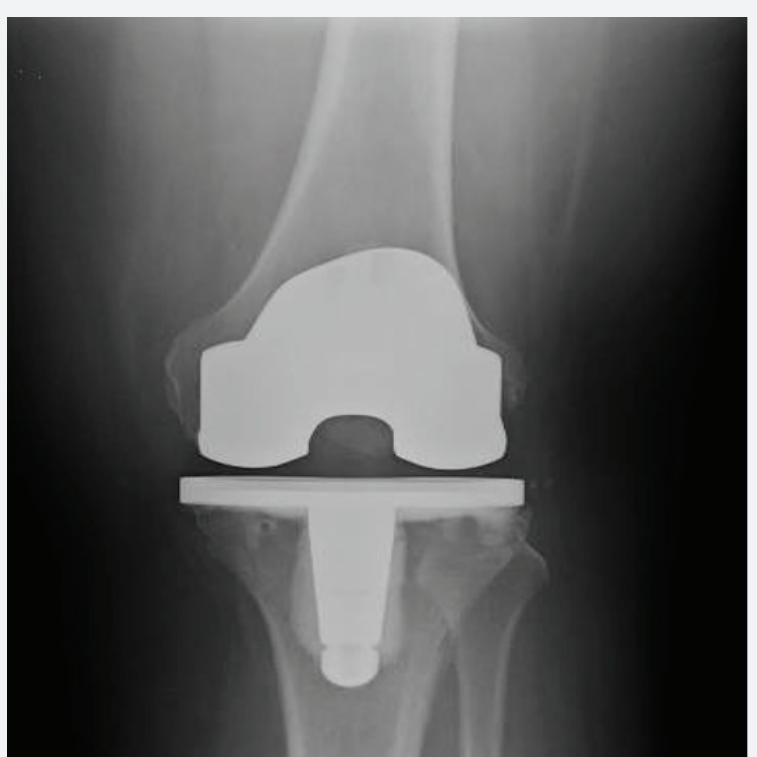

Figure 4: AP radiograph of left knee demonstrating well placed prosthesis at 2-year follow-up.

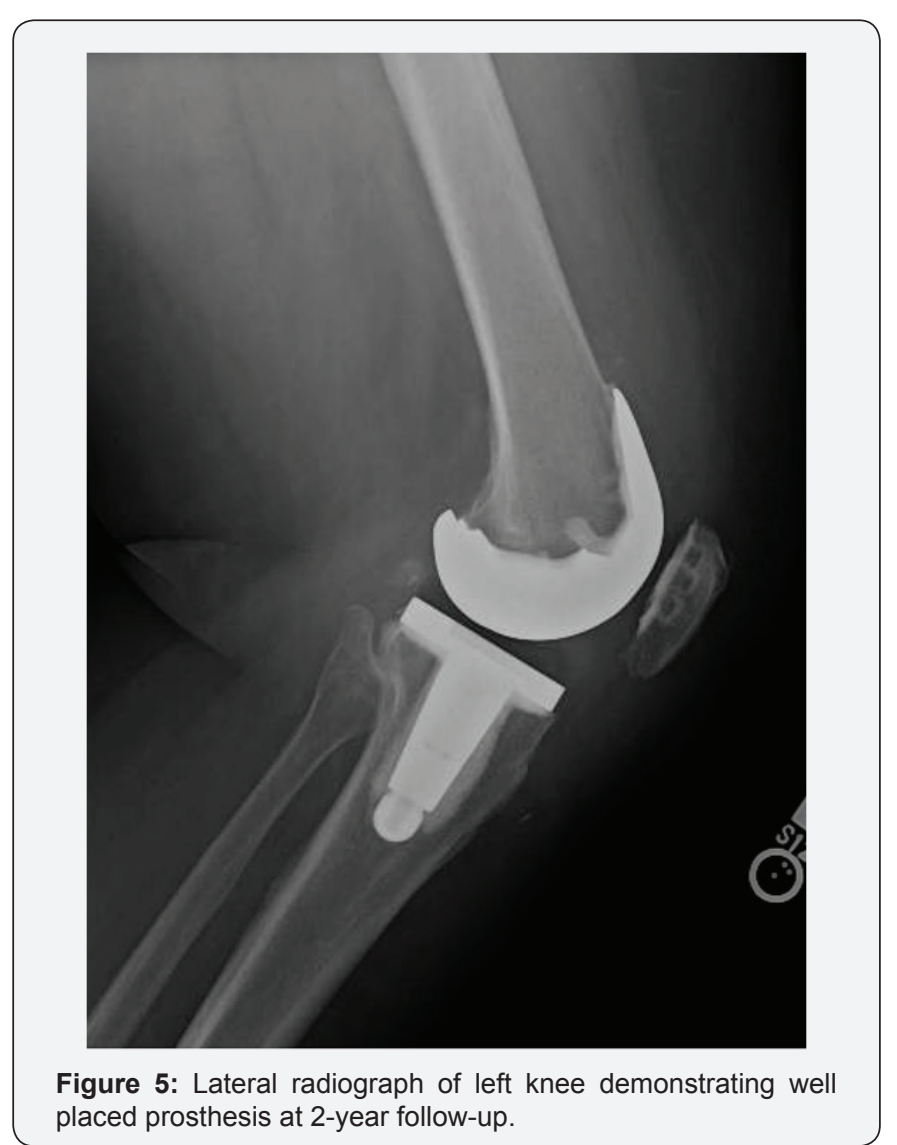

\section{Discussion}

This report details a yet-reported complication on total knee replacement: a patient swallowing their dentures in the early post-operative period. Approximately $20 \%$ of adults between the ages of 18 and 74 wear dentures [2,3]. Despite the prevalence of denture use in the population cases of swallowed dentures are uncommon in medical literature with less than 75 cases reported from 2000-2015 [3]. While accidental ingestion of dentures is rare these cases have the potential to cause serious morbidity and even mortality in patients. Therefore, early identification and management are recommended.

Swallowed denture usually presents similarly to other cases of foreign body ingestion. Common presenting complaints include dysphagia, odynophagia, and inability to swallow saliva, and throat pain or fullness. Interestingly, the presenting symptom of our patient, intractable nausea, is not a commonly reported symptom in the literature. Often the patients report that they have swallowed their dentures, although this is not always the case as demented, delirious, and intoxicated patients are at increased risk of accidental ingestion of dentures and may not reliably report the event [4]. In fact, there are reports in the literature of a presentation for swallowed dentures 4 years after the event occurred [5,6]. Additionally in the inpatient hospital setting it is not uncommon for personal items to be misplaced, as patients move between rooms for operations, procedures, and imaging. This can add to the difficulty of diagnosis in the inpatient setting because it may be more likely that the patients 


\section{Orthopedics and Rheumatology Open Access Journal}

presenting symptoms stem from other more common medical issues and that the dentures were simply lost or misplaced.

Ingested dentures provide a diagnostic challenge with imaging as the majority of dentures are made of radiolucent acrylic material, often without any metallic clasp or wire [7]. One finding that may suggest swallowed denture is air entrapment around the denture and increase in the prevertebral soft tissues, although this is a non-specific finding $[7,8]$. Fortunately, in our case the dentures were visible with plain radiograph. However, if clinical suspicion of ingested denture is high and plain radiograph is negative for dentures, then CT provides a more sensitive alternative. Unenhanced CT is considered the gold standard for definitive diagnosis of swallowed dentures. Dentures appear as hyper dense curvilinear structure with focal hyper dense protrusions representing the prosthetic teeth [7]. Knowledge of common choke points in the GI system may aid in the search for swallowed dentures. The most common choke point is in the upper GI tract between C6 and T2 [7,8]. Flexible or rigid endoscopy can be both diagnostic and therapeutic for swallowed dentures [9].

There are 3 major options in management for swallowed dentures: observation, endoscopy, and surgery. Dentures fall into the category of sharp foreign body and therefore endoscopic removal is often warranted. Smaller dentures (up to $3 \mathrm{~cm}$ in size) can usually pass without incident, while larger dentures may require removal either via endoscopy or surgery [8]. Management choice can also be based on the location of the dentures at time of presentation. For dentures located proximal to the ligament of Treitz endoscopy is suggested, while observation is preferred for those located distally. Some authors suggest that intervention is always recommended, due to the danger of perforation, obstruction, and fistula formation $[6,7]$. There is controversy as some authors suggest that dentures with metallic components have higher tendency to impact and cause perforation [4]. Consultation by general surgery and/ or dentistry is usually warranted in case of trauma from sharp edges of the dental prosthesis.

\section{Conclusion}

In our case the dentures were first noted in the lower esophagus on plain radiograph. The literature suggests that the ideal management of this case would be endoscopic removal of the dentures. Therefore, our case adds to the uncertainty in best management strategy, as the patient was able to pass the dentures with no ill effects. Due to the rarity of this clinical scenario there is little strong evidence for best management. Subsequently physicians should use their clinical judgment and that of consulting providers in management of ingested dentures.

Above we have reviewed the common presentation, diagnosis, and management of swallowed dentures. This case serves as a reminder that even in extremely common surgeries, such as total knee arthroplasty, bizarre and unforeseen complications may occur. Therefore, physicians should be prepared for unusual circumstances and listen to and respect the patient's story and input on their condition, no matter how unbelievable the story may sound.

\section{References}

1. Steiner C, Andrews R, Barrett M, Weiss A (2012) HCUP Projections: Mobility/Orthopedic Procedures 2003 to 2012. In. HCUP Projections Report 2012-03: US Agency for Healthcare Research and Quality, USA.

2. Redford M, Drury TF, Kingman A, Brown LJ (1996) Denture use and the technical quality of dental prostheses among persons 18-74 years of age: United States, 1988-1991. J Dent Res 75: 714-725.

3. Kent SJ, Mackie J, Macfarlane TV (2016) Designing for Safety: Implications of a Fifteen Year Review of Swallowed and Aspirated Dentures. J Oral Maxillofac Res 7(2): e3.

4. Hashmi S, Walter J, Smith W, Latis S (2004) Swallowed partial dentures. J R Soc Med 97(2): 72-75.

5. Odigie VI, Yusufu LM, Abur P, Edaigbini SA, Dawotola DA, Mai A, et al. (2011) Broncho-Oesophageal Fistula (BOF) Secondary to Missing Partial Denture in an Alcoholic in a Low Resource Country. Oman Med J 26(1): 50-52.

6. Gunjan D, Rana SS, Gupta R, Bhasin DK (2015) Tracheo-esophageal fistula following spontaneous migration of a missed impacted denture. Endoscopy. 47: E331-332.

7. Chawla A, Bosco J, Subramanian M, Chokkapan K, Shenoy J, et al. (2015) Imaging findings of swallowed dentures: a case series. Emerg Radiol 22(6): 717-721.

8. Gachabayov M, Isaev M, Orujova L, Isaev E, Yaskin E, et al. (2015) Swallowed dentures: Two cases and a review. Ann Med Surg (Lond) 4(4): 407-413.

9. Jain S, Yadav HP, Shivhare R (2015) Accidental Swallowing of Mandibular Partial Denture. J Clin Diagn Res 9(8): ZJ01.

\begin{tabular}{l} 
Your next Submission with Juniper Publishers \\
will reach you the below assets \\
- Quality Editorial service \\
- Swift Peer Review \\
- Reprints availability \\
- E-prints Service \\
- Manuscript Podcast for convenient understanding \\
- Global attainment for your research \\
- Manuscript accessibility in different formats \\
( Pdf, E-pub, Full Text, Audio) \\
- Unceasing customer service \\
Track the below URL for one-step submission \\
https://juniperpublishers.com/online-submission.php \\
\hline
\end{tabular}

